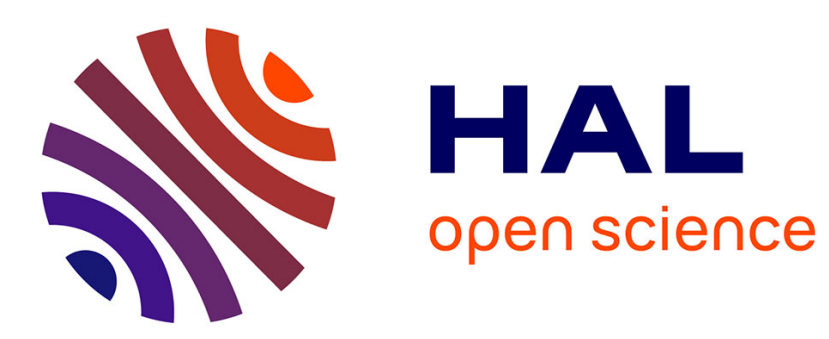

\title{
The effect of structural relaxation on SANS and its anisotropy in a metallic glass
}

A.R. Yavari

\section{To cite this version:}

A.R. Yavari. The effect of structural relaxation on SANS and its anisotropy in a metallic glass. Journal de Physique Lettres, 1985, 46 (5), pp.189-193. 10.1051/jphyslet:01985004605018900 . jpa-00232498

\section{HAL Id: jpa-00232498 https://hal.science/jpa-00232498}

Submitted on 1 Jan 1985

HAL is a multi-disciplinary open access archive for the deposit and dissemination of scientific research documents, whether they are published or not. The documents may come from teaching and research institutions in France or abroad, or from public or private research centers.
L'archive ouverte pluridisciplinaire HAL, est destinée au dépôt et à la diffusion de documents scientifiques de niveau recherche, publiés ou non, émanant des établissements d'enseignement et de recherche français ou étrangers, des laboratoires publics ou privés. 


\title{
The effect of structural relaxation on SANS and its anisotropy in a metallic glass $\left(^{*}\right)$
}

\author{
A. R. Yavari \\ Laboratoire de Thermodynamique et Physico-Chimie Métallurgiques $\left({ }^{+}\right)$, INPG, B.P. 75, \\ Domaine Universitaire, 38402 Saint Martin d'Hères Cedex, France
}

(Reçu le 5 novembre 1984, accepté le 8 janvier 1985)

\begin{abstract}
Résumé. - Nous avons mesuré une baisse sensible de la diffusion des neutrons aux petits angles (DNPA) dans le verre métallique $\mathrm{Pd}_{80} \mathrm{Si}_{12} \mathrm{Ge}_{8}$ après un recuit de relaxation en dessous de $1_{2}$. Dans un article précédent, nous avons attribué la DNPA et son anisotropie mesurées dans les rubans amorphes bruts de trempe aux défauts piégés et leur orientation préférée induite par le cisaillement du liquide par le substrat pendant la solidification ultra-rapide. Nous attribuons maintenant la baisse sensible de la DNPA enregistrée dans le ruban amorphe recuit à la disparition d'une partie des défauts piégés lors de la trempe. Une contribution majeure des cristallites ou des surfaces est exclue car elle n'aurait pas induit une baisse de l'intensité diffusée.
\end{abstract}

\begin{abstract}
We report a large decrease in small-angle-neutron scattering (SANS) after relaxationannealing below $T_{\mathrm{g}}$ in glassy $\mathrm{Pd}_{80} \mathrm{Si}_{12} \mathrm{Ge}_{8}$ ribbons. We had previously reported here on the SANS in this alloy and its anisotropy which we attributed to defect orientations induced by the shearing action of the substrate during rapid solidification. We now attribute the decrease in the anisotropic SANS to the partial disappearance of these quenched-in defects during the relaxation anneal. Important contributions from crystallites and surface effects are excluded as they would tend to increase and not decrease the SANS.
\end{abstract}

\section{Introduction.}

In a recent Letter in this journal, we reported observation of anisotropic small-angle-neutron scattering (SANS) intensity from ribbons of metallic glasses [1] which we attributed to a preferredorientation of defects in the ribbon plane with their long axis along the ribbon length. We had previously suggested that substrate-induced shearing of the undercooled melt during rapid solidification should result in such orientations of quenched-in defects [2].

Since then, measurements have revealed other structural anisotropies in metallic glasses with significant differences in mechanical and magnetic properties measured along and across the casting direction [3-6]. Part of the anisotropy can be removed by relaxation annealing at temperatures below the crystallization temperature $T_{x}[5,6]$. Another part however remains until the onset of crystallization at $T_{\mathrm{x}}[3,4]$ and has been attributed also to shear induced mediumrange-order (MRO) anisotropy [4].

(*) The SANS measurements were carried out at ILL.

$\left({ }^{+}\right)$LTPCM, LA No 29 au CNRS. 
These observations are complementary to our results reported here [1] on SANS in metallic glasses. The reported preferred-orientation of defects has also been discussed in connection with the momentum versus thermal boundary layer controlled solidification [7,8]. Some doubt remained however as to the possible contribution of surface scattering $[9,10]$ in the scattering vector, $Q$, range of our previous report. In particular, it could be argued that the melt-spun ribbon surface which comes in contact with the substrate is highly perturbed and marked by polishing lines and gas pockets on the substrate (see Fig. 1). We have therefore designed and conducted new experiments on the evolution of SANS with relaxation annealing [11].

In this Letter we show clearly that the SANS in melt-spun $\mathrm{Pd}_{80} \mathrm{Si}_{12} \mathrm{Ge}_{8}$ glassy ribbons reported in our previous Letter [1] is due to quenched-in defects which can, to a large extent, be removed by proper post-quench relaxation-annealing without crystallization.

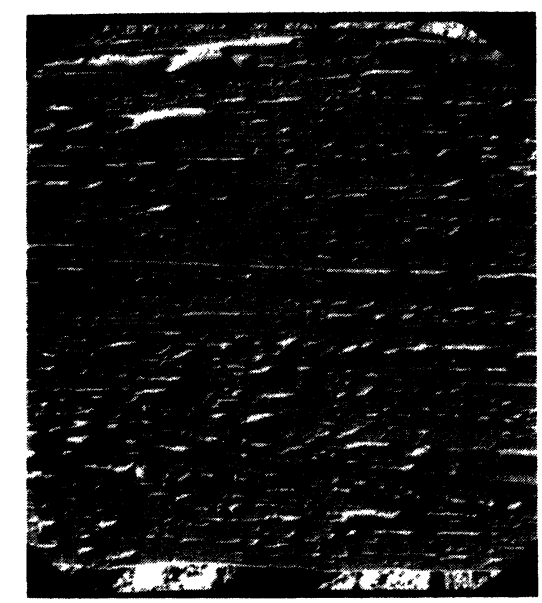

Fig. 1. - Electron-micrograph of the substrate side of $\simeq 2 \mathrm{~mm}$ wide amorphous $\mathrm{Pd}_{80} \mathrm{Si}_{12} \mathrm{Ge}_{8}$ ribbon (magnification $\times 24$ ).

\section{Experimental procedure.}

The melt-spun amorphous $\mathrm{Pd}_{80} \mathrm{Si}_{12} \mathrm{Ge}_{8}$ alloy ribbon used in this experiment was prepared on the melt-spinning apparatus at LTPCM. The ribbon was $25 \mu \mathrm{m}$ thick, $2 \mathrm{~mm}$ wide and $20 \mathrm{~m}$ long. As before, this ribbon was wrapped around a frame so as to form parallel layers with total thickness $\simeq 0.4 \mathrm{~mm}$ for the scattering experiment, conducted on the D11 spectrometer at ILL [12] with incident beam wave length $\lambda \simeq 1 \mathrm{~nm}$ and sample detector distance of $10.6 \mathrm{~m}$. The parallel ribbon layers were placed parallel to the 2-dimensional multi-detector with ribbon long axis along the vertical direction. In this configuration the detector plane corresponds to the plane of scattering vector $Q=4 \pi \sin \theta / \lambda$ with the vertical and horizontal $Q$ axes being parallel to the ribbon length and width respectively ( $2 \theta$ is the scattering angle). The coherent scattered intensity $I(Q)=\mathrm{d} \sigma / \mathrm{d} \Omega$ in barns was obtained from the measured intensities as described in [11].

The alloy composition $\mathrm{Pd}_{80} \mathrm{Si}_{12} \mathrm{Ge}_{8}$ was chosen to obtain equality between the average metalloid coherent scattering length and that of palladium. This allows the preferential observation of density defects and suppresses the scattering by metal-metalloid composition fluctuations $[7,13]$.

Furthermore, as shown in the DSC thermogram of figure 2, the alloy exhibits a glass-transition at $T_{\mathrm{g}} \simeq 660 \mathrm{~K}$, well below its crystallization temperature $T_{\mathrm{x}} \simeq 690 \mathrm{~K}$ indicating good stability of the amorphous phase and allowing heat-treatments below $T_{\mathrm{g}}$ without the possibility of partial 


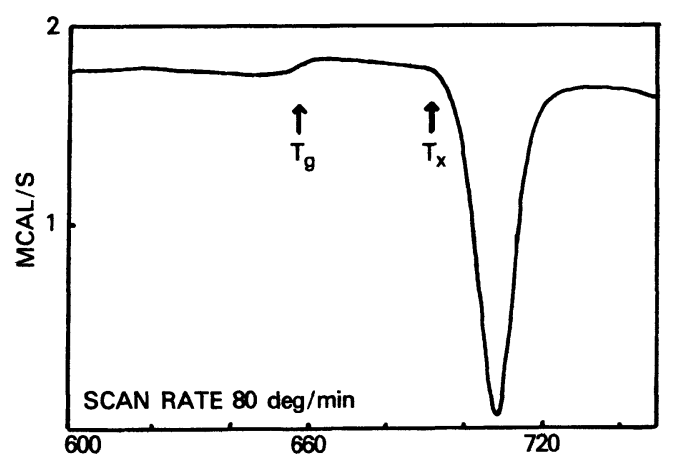

Fig. 2. - DSC thermogram of amorphous $\mathrm{Pd}_{80} \mathrm{Si}_{12} \mathrm{Ge}_{8}$ prepared by melt-spinning.

crystallization. For example, for the sister composition $\mathrm{Pd}_{80} \mathrm{Si}_{20}$, it has been demonstrated [14] that a relaxation-anneal at $543 \mathrm{~K}$ can result in significant modification of $\mathrm{X}$-ray interference functions without crystallization. Part of the ribbons were therefore annealed in a sealed pyrex tube under vacuum for $30 \mathrm{~min}$ at $543 \mathrm{~K}$. The ribbons remained ductile after annealing and X-ray diffraction tests showed no evidence of crystallinity after the anneal.

\section{Results and discussion.}

In our first report on the subject [1] we attributed the observed SANS and its anisotropy to a preferred orientation of anisometric defects caused by the substrate shearing action during solidification. If the scatterers are density defects, they should at least partially anneal out during a relaxation anneal at $T \ll T_{\mathrm{g}}$. Figure 3 shows coherent scattering intensities $I(Q)$ versus $Q$ curves for melt-spun $\mathrm{Pd}_{80} \mathrm{Si}_{12} \mathrm{Ge}_{8}$ in the as-quenched state and after annealing at $543 \mathrm{~K}$. Also shown is $I(Q)$ vs. $Q$ for a $20 \mathrm{~mm}$ wide glassy ribbon of the same alloy prepared by planar-flow-casting (PCF) $[13,15]$. The wider ribbon is expected to have undergone a slower quench. The results are consistent with the attribution of the SANS to quenched-in density defects. The more rapidly quenched narrow, melt-spun ribbon scatters more than the wide ribbon. Furthermore, the

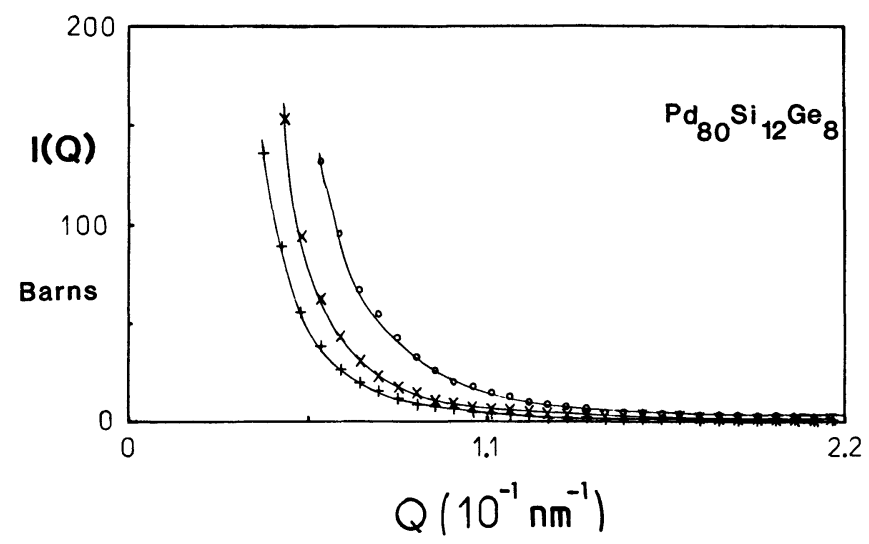

Fig. 3. - SANS intensity $I(Q)$ in narrow as-quenched $(\circ)$ and annealed $(x)$ melt-spun ribbon [11] compared to wide as-quenched $(+)$ ribbon of the same composition [13] prepared by planar-flow-casting [15]. 
SANS intensity in the narrow ribbon drops sharply after the short anneal towards the curve for the wide ribbon indicating partial disappearance of the quenched-in scattering defects after relaxation annealing.

Figure 4 shows the scattered intensity $I(Q)$ for the annealed and as-quenched narrow ribbons with $Q$ parallel and perpendicular to the ribbon length. In this figure the SANS anisotropy is more clearly seen than in the data presented previously [1] due to the lower range of $Q$. Again SANS is more intense for $Q_{\perp}$ to the ribbon length indicating defects elongated along the ribbon casting direction. The scattered intensity $I(Q)$ is seen to diminish after annealing along both $Q_{\|}$and $Q_{\perp}$ to the casting direction. We note that scattering due to the emergence of crystallites during the anneal should increase rather than decrease the SANS. Furthermore, any contribution from surface scattering is expected to remain constant with annealing or increase due to the formation of oxide layers or superficial segregation [16] but in no case should it decrease with annealing below $T_{\mathrm{g}}$. The reduction in the anisotropic SANS with annealing tends therefore to support the suggestion of the existence of quenched-in orientations of anisometric density defects. Guinier's plots of the SANS show linear regions only at higher $Q$ values with slopes $R_{\mathrm{g}}^{2} / 3$ such that the product $R_{\mathrm{g}} Q>1.5$ is beyond the range of validity of the Guinier approximation. We have however, previously given an approximate radius of gyration of the order of $20 \mathrm{~nm}$ for ellipsoids or thin discs in the ribbon plane with their long axis along the ribbon-length and being less than $1 \mathrm{~nm}$ along the ribbon thickness [1,7]. Cigar shaped defects have also been mentioned [7] but we are most likely dealing with a distribution of defect size and shapes.

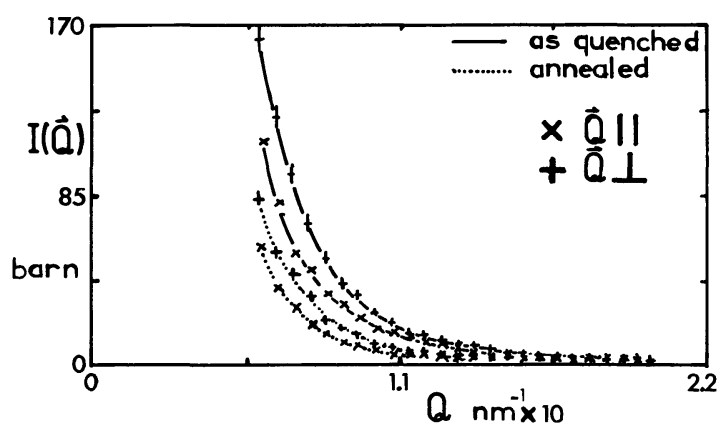

Fig. 4. - SANS intensity $I(Q)$ in narrow as-quenched $(-)$ and annealed $(\cdots)$ amorphous melt-spun $\mathrm{Pd}_{80} \mathrm{Si}_{12} \mathrm{Ge}_{8}$ with wave-vector $\mathbf{Q}$ along the ribbon length $(\times)$ and width $(+)$.

Other workers have attributed SANS in this $Q$ range in metallic glasses to quasi-dislocations [17]. Figure 5 shows $\ln I(Q)$ vs. $\ln Q$ plots of the melt-spun Pd-based glassy ribbon before and

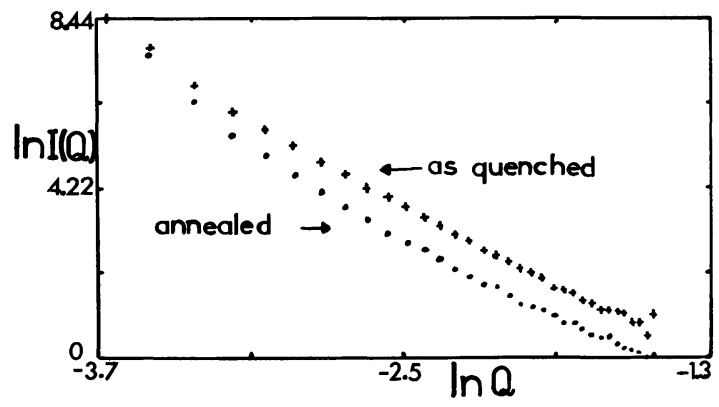

Fig. 5. $-\ln I(Q)$ versus $\ln Q$ curves for as-quenched $(+)$ and annealed $(\bullet)$ amorphous melt-spun $\mathrm{Pd}_{80} \dot{\mathrm{Si}}_{12} \mathrm{Ge}_{8}$ ribbon. 
after annealing. An over-all slope of $\simeq-3.4$ is observed for $|Q| \geqslant 5 \times 10^{-2} \mathrm{~nm}^{-1}$. At lower $Q$ values, the scattering curves for the two samples converge. This can be attributed to the predominance of surface scattering at these very low angles. This and other information on surface scattering will be presented in detail elsewhere.

\section{Acknowledgments.}

The author would like to thank Drs. M. Maret and P. Chieux for precious help during the ILL experiment [11] and Mr. Denis Bijaoui for the long hours he devoted to the careful correction and processing of the numerous neutron SANS spectra obtained in the experiment reported in [11].

\section{References}

[1] Yavari, A. R. and Maret, M., J. Physique Lett. 44 (1983) L-553.

[2] Yavari, A. R., Hicter, P. and Desré, P., Proc. 4th Int. Conf. on Rapidly Quenched Metals, T. Masumoto and K. Suzuki eds. 1 (1981) 713.

[3] Arakawa, S., Harada, H., Hausch, G., Hilzinger, H. R., Menges, F. J. and Warlimont, H., Proc. 5th Int. Conf. on Rapidly Quenched Metals, H. Warlimont and P. Steeb eds., Wurzburg 1984.

[4] Morita, H., Obi, Y. and Fujimori, H., Proc. 5th Int. Conf. on Rapidly Quenched Metals, H. Warlimont and P. Steeb eds., Wurzburg 1984.

[5] Yavari, A. R., Proc. 5th Int. Conf. on Rapidly Quenched Metals, H. Warlimont and P. Steeb eds., Wurzburg 1984.

[6] Cahn, R. W., Pratten, N. A., Scott, M. G., Sinning, H. R. and Leonardson, L., Symposium on rapidly Solidified Metastable Mat., B. H. Kear and B. C. Giessen eds., MRS, Boston 1983.

[7] Yavari, A. R. and Desré, P., J. Phys. F 14 (1984) 291.

[8] Davies, H. A., Vincent, J. H. and Herbertson, J. G., J. Phys. F 14 (1984) 2007.

[9] Roth, M., J. Appl. Cryst. 10 (1977) 172.

[10] Rodmacq, B., Mangin, Ph. and Chamberod, A., Phys. Rev. B 30 (1984) 6188.

[11] Yavari, A. R., Bijaoui, D., Maret, M. and Chieux, P., Symposium on Amorphous and Non-Equilibrium Processing, MRS-Europe, Strasbourg 1984 (Les Editions de Physique) 1984, p. 281.

[12] Ibel, K., J. Appl. Cryst. 9 (1976) 296.

[13] Yavari, A. R., Joud, J. C. and Bellissent, M. C., Phys. Lett. A 105 (1984) 88.

[14] Waseda, Y. and Egami, T., J. Mater. Sci. 14 (1979) 1249.

[15] Casanova, P., Joud, J. C., Senillou, C. and Yavari, A. R., Mémoires et Etudes Scientifiques, Revue de Métallurgie, oct. 1984, p. 553.

[16] Bijaoui, D., Yavari, A. R., Wasselin, J. and Joud, J. C., Symposium on Amorphous and Non-Equilibrium Processing, MRS-Europe, Strasbourg 1984 (Les Editions de Physique) 1984, p. 171.

[17] Nold, E., Steeb, S., Lamparter, P. and Rainer-Harbach, G., J. Physique Colloq. 41 (1980) C8-86. 